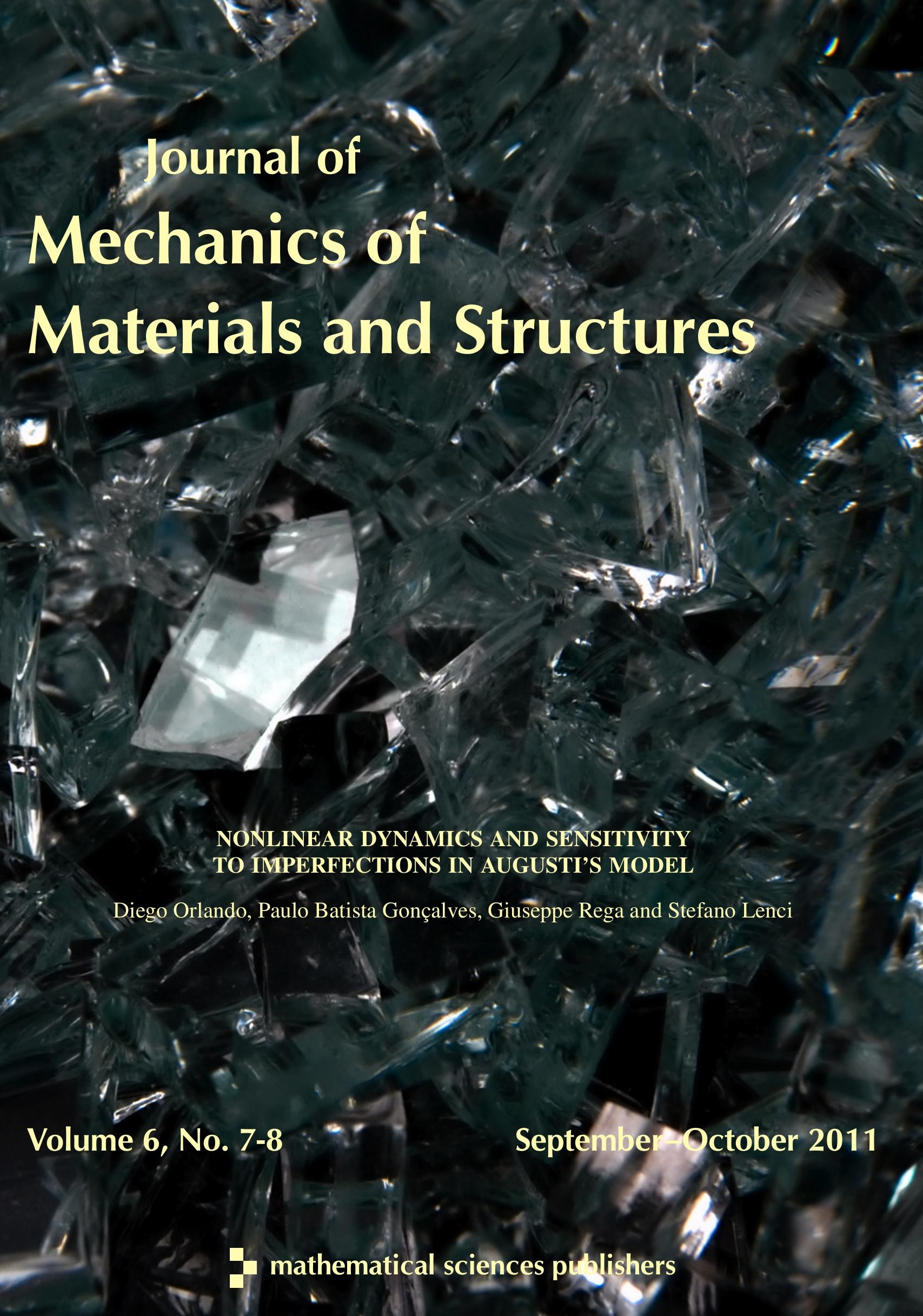




\title{
NONLINEAR DYNAMICS AND SENSITIVITY TO IMPERFECTIONS IN AUGUSTI'S MODEL
}

\author{
Diego Orlando, Paulo Batista Gonçalves, Giuseppe Rega and Stefano Lenci
}

The influence of geometric imperfections on the nonlinear behavior and stability of Augusti's model under static and dynamic loads is analyzed. This 2-DOF lumped-parameter system is an archetypal model of modal interaction in stability theory representing a large class of structural problems. When the system displays coincident buckling loads, several postbuckling paths emerge from the bifurcation point (critical load) along the fundamental path, in particular coupled unstable postbuckling paths that control the nonlinear dynamics of the system for load levels lower than the critical load. Systems displaying unstable postbuckling behavior are particularly sensitive to initial imperfections. They decrease the static buckling load and distort the topology of the safe potential well. Herein, coupled/uncoupled dynamic responses, bifurcations, escape from the prebuckling potential well, stability, space-time-varying displacements, and attractor-manifold-basin phase portraits are numerically evaluated with the aim of enlightening the effect of system imperfection sensitivity. In particular, the investigation of the reduction of escape load for several varying system parameters highlights the remarkable loss of safety and dynamic integrity of the structure due to penetration of eroding fractal tongues into the safe basin.

\section{Introduction}

The influence of imperfections on bifurcations can be traced back at least to [Koiter 1945] in problems of elastic stability and [Zocher 1933] in problems involving liquid crystals. A mathematical treatment of the problem can be found, for example, in [Iooss and Joseph 1980]. Analysis of the imperfection sensitivity of simplified models exhibiting different types of bifurcation under static loads can be found in [Croll and Walker 1972; Thompson and Hunt 1973; 1984; Naschie 1990], among others. These models have been used to demonstrate the nonlinear behavior and stability of several classes of structures. The influence of imperfection is particularly important in systems liable to postbuckling behavior. One area where the study of imperfection sensitivity is essential is the analysis of systems where the interaction of different buckling modes with equal or nearly equal bifurcation loads may conspire to increase or even generate unstable postbuckling paths.

Augusti's model constitutes an archetypal model for this class of problems [Augusti 1964]. Static analysis of this model can be found in, for example, [Croll and Walker 1972; Bažant and Cedolin 1991; Pignataro et al. 1991; Raftoyiannis and Kounadis 2000]. Augusti's model represents a large class of structures where the postbuckling behavior is controlled by modal coupling. This model may present two equal or nearly equal critical loads associated with two different critical modes. When the modes

The authors acknowledge the financial support of the Brazilian research agencies CAPES, CNPq and FAPERJ-CNE..

Keywords: Augusti's model, modal coupling, nonlinear oscillations, imperfection sensitivity, dynamic instability,

load-carrying capacity. 
are analyzed separately, the structure exhibits a stable symmetric postbuckling behavior. However, when the modal coupling is taken into account, apart from the uncoupled solutions, which become unstable, new coupled unstable paths emerge from the bifurcation points. These unstable coupled paths delimit the safe prebuckling well and the magnitude of the perturbations that the structure can withstand without escaping from the safe well. Continuous structures displaying coincident or nearly coincident buckling loads, are, among others, plates, shells, cold-formed struts, and some frame structures [Tvergaard 1973; Bažant and Cedolin 1991; Kiymaz 2005; Chen and Yu 2006; Brubak and Hellesland 2007; Dinis et al. 2007; Kołakowski 2007; Quinn et al. 2007]. A particularly notorious case is the cylindrical shell under axial compression, which, as shown in [Koiter 1945], may display for certain geometries an infinite number of coincident buckling loads [Heijden 2008]. Another interesting model in the static context proposed by Augusti was thoroughly investigated in [Elishakoff et al. 1996].

The influence of modal coupling on the nonlinear dynamics of Augusti's model has been addressed in [Gonçalves et al. 2009]. Here, upon formulating the mechanical problem for the system with imperfections (Section 2), a detailed parametric analysis shows the influence of geometric imperfections on the buckling and postbuckling behavior of Augusti's model and how the unstable solutions control the global behavior of the system (Section 3.1). The analysis of the system under harmonic base excitation and different forcing directions clarifies the importance of the imperfections on the dynamics through the analysis of bifurcation diagrams and the evolution of basins of attraction, focusing on the evaluation of system load-carrying capacity (Section 3.2). Although this constitutes an important issue in nonlinear structural dynamics, little is known on the influence of imperfections on the nonlinear dynamics of structures liable to unstable postbuckling behavior.

\section{Formulation of the problem}

Figure 1a illustrates Augusti's model. It is an inverted spatial pendulum composed of a slender, rigid (but massless) bar of length $l$, with a tip-mass $m$, pinned at the base, where two rotational springs with constant stiffnesses $k_{1}$ and $k_{2}$ initially act in perpendicular planes and rotate with the bar. The angles

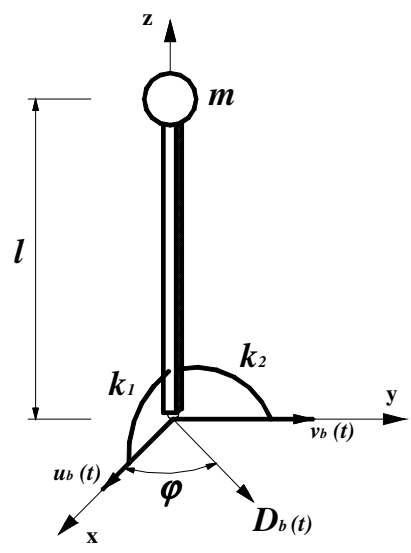

(a)



(b)

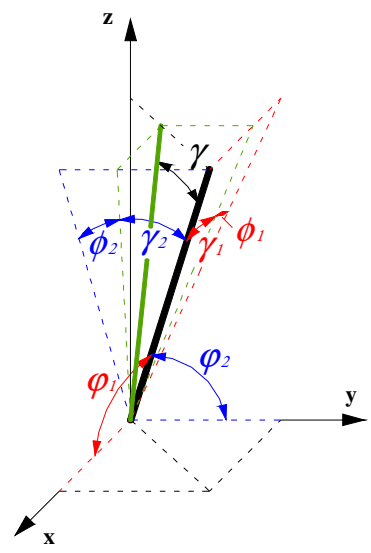

(c)

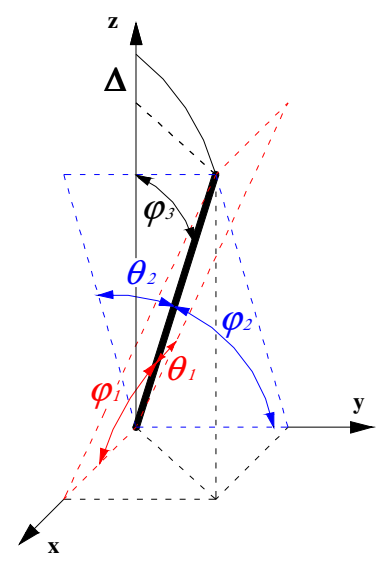

(d)

Figure 1. Augusti's 2-DOF model. Perfect system: undeformed (a) and deformed (d); imperfect system: undeformed (b) and deformed (c, d). 
$\theta_{1}$ and $\theta_{2}$ (Figure 1d) are chosen as the two DOFs. Figure 1a shows the system under a harmonic base excitation $D_{b}(t)$, acting at an angle $\varphi$ with respect to the $x$ axis. The force $D_{b}(t)$ is decomposed into two components, $u_{b}(t)$ in the $x$ direction and $v_{b}(t)$ in the $y$ direction. These components are given by $u_{b}=F_{b} \cos \varphi \sin \left(\omega_{e} t\right)$ and $v_{b}=F_{b} \sin \varphi \sin \left(\omega_{e} t\right)$, where $F_{b}$ is the forcing magnitude and $\omega_{e}$ is the forcing frequency. Figure 1 shows the auxiliary variables necessary for the derivation of the equations of motion of the imperfect system. The initial configuration of the geometrically imperfect column is defined by the angles $\phi$ and $\psi$ shown in Figure 1b, where the two angles $\varphi_{10}$ and $\varphi_{20}$ are also reported. The angles $\phi_{1}$ and $\phi_{2}$ are the geometric imperfections of the two torsional springs and $\gamma_{1}$ and $\gamma_{2}$ are their deformations in the $\theta_{1}$ and $\theta_{2}$ directions (see Figure 1c). The following expressions hold:

$$
\varphi_{3}=\phi+\gamma, \quad \theta_{1}=\phi_{1}+\gamma_{1}, \quad \theta_{2}=\phi_{2}+\gamma_{2},
$$

$\varphi_{1}, \varphi_{2}$, and $\varphi_{3}$ being the angles of the imperfect pendulum with the three axes in the deformed configuration (Figure 1d).

The dimensionless total potential energy of the system is given by [Orlando 2010]

$$
\bar{V}=\frac{V}{m l^{2}}=\frac{1}{2} \frac{\omega_{p}^{2}}{\lambda}\left(\theta_{1}-\phi_{1}\right)^{2}+\frac{1}{2} \frac{\omega_{p}^{2}}{\lambda}\left(\theta_{2}-\phi_{2}\right)^{2}-\omega_{p}^{2}\left(\sqrt{1-\sin ^{2} \phi_{1}-\sin ^{2} \phi_{2}}-\sqrt{1-\sin ^{2} \theta_{1}-\sin ^{2} \theta_{2}}\right),
$$

where $P=m g, \omega_{p}^{2}=g / l, \lambda=P / P_{\mathrm{cr}}, k / m l^{2}=\omega_{p}^{2} / \lambda, k_{1}=k_{2}=k$, and $P_{\mathrm{cr} 1}=P_{\mathrm{cr} 2}=P_{\mathrm{cr}}=k / l$, with $\omega_{p}$ and $P_{\mathrm{cr}}$ being the pendulum natural frequency and buckling load, respectively, while the dimensionless kinetic energy is written as

$$
\bar{T}=\frac{T}{m l^{2}}=\frac{1}{2 l^{2}}\left(\left(l \dot{\theta}_{1} \cos \theta_{1}+\dot{u}_{b}\right)^{2}+\left(l \dot{\theta}_{2} \cos \theta_{2}+\dot{v}_{b}\right)^{2}+\frac{l^{2}\left(\dot{\theta}_{1} \cos \theta_{1} \sin \theta_{1}+\dot{\theta}_{2} \cos \theta_{2} \sin \theta_{2}\right)^{2}}{\cos ^{2} \theta_{1}+\cos ^{2} \theta_{2}-1}\right),
$$

where the dot indicates differentiation with respect to time $t$.

Using Hamilton's principle of least action, the equations of motion of the system are obtained as the extremals of the functional $\Phi=\int_{t_{1}}^{t_{2}} L d t, L$ being the Lagrangian. Then the evolution of $\theta_{i}$ with time is subjected to the Euler-Lagrange equations of motion:

$$
\frac{d}{d t} \frac{\partial(\bar{T})}{\partial \dot{\theta}_{i}}-\frac{\partial(\bar{T})}{\partial \theta_{i}}+\frac{\partial(\bar{V})}{\partial \theta_{i}}=0
$$

Considering also a viscous damping for the geometrically imperfect Augusti's model, the equations of motion in terms of the generalized coordinates $\theta_{1}$ and $\theta_{2}$ are given explicitly by [Orlando 2010]

$\left(\ddot{\theta}_{1}\left(-\cos ^{2} \theta_{1} \cos ^{2} \theta_{2}+\cos ^{4} \theta_{1} \cos ^{2} \theta_{2}+\cos ^{2} \theta_{1} \cos ^{4} \theta_{2}\right)+\ddot{\theta}_{2}\left(-\cos \theta_{1} \sin \theta_{1} \cos \theta_{2} \sin \theta_{2}\right.\right.$ $\left.+\cos ^{3} \theta_{1} \sin \theta_{1} \cos \theta_{2} \sin \theta_{2}+\cos \theta_{1} \sin \theta_{1} \cos ^{3} \theta_{2} \sin \theta_{2}\right)+\dot{\theta}_{1}^{2}\left(-\cos \theta_{1} \sin \theta_{1} \cos ^{4} \theta_{2}+\cos \theta_{1} \sin \theta_{1} \cos ^{2} \theta_{2}\right)$ $+\dot{\theta}_{2}^{2}\left(\cos \theta_{1} \sin \theta_{1}-2 \cos \theta_{1} \sin \theta_{1} \cos ^{2} \theta_{2}-\cos ^{3} \theta_{1} \sin \theta_{1}+2 \cos ^{3} \theta_{1} \cos ^{2} \theta_{2} \sin \theta_{1}+\cos \theta_{1} \cos ^{4} \theta_{2} \sin \theta_{1}\right)$ $\left.+\dot{\theta}_{1} \dot{\theta}_{2}\left(2 \cos ^{2} \theta_{1} \cos \theta_{2} \sin \theta_{2}-2 \cos ^{4} \theta_{1} \cos \theta_{2} \sin \theta_{2}\right)\right)+\left(\frac{2 \xi_{1}}{\Omega} \dot{\theta}_{1}+\frac{\theta_{1}-\phi_{1}}{\lambda \Omega^{2}}-\frac{1}{\Omega^{2}} \frac{\cos \theta_{1} \sin \theta_{1}}{\sqrt{1-\sin ^{2} \theta_{1}-\sin ^{2} \theta_{2}}}\right)$ $\times\left(1-2 \cos ^{2} \theta_{1}-2 \cos ^{2} \theta_{2}+\cos ^{4} \theta_{1}+\cos ^{4} \theta_{2}+2 \cos ^{2} \theta_{1} \cos ^{2} \theta_{2}\right)$ $=F \cos \varphi \sin \tau \cos \theta_{1}\left(1-2 \cos ^{2} \theta_{1}-2 \cos ^{2} \theta_{2}+\cos ^{4} \theta_{1}+\cos ^{4} \theta_{2}+2 \cos ^{2} \theta_{1} \cos ^{2} \theta_{2}\right)$, 
$\left(\ddot{\theta}_{2}\left(-\cos ^{2} \theta_{1} \cos ^{2} \theta_{2}+\cos ^{4} \theta_{1} \cos ^{2} \theta_{2}+\cos ^{2} \theta_{1} \cos ^{4} \theta_{2}\right)+\ddot{\theta}_{1}\left(-\cos \theta_{1} \sin \theta_{1} \cos \theta_{2} \sin \theta_{2}\right.\right.$ $\left.+\cos ^{3} \theta_{1} \sin \theta_{1} \cos \theta_{2} \sin \theta_{2}+\cos \theta_{1} \sin \theta_{1} \cos ^{3} \theta_{2} \sin \theta_{2}\right)+\dot{\theta}_{2}^{2}\left(-\cos ^{4} \theta_{1} \cos \theta_{2} \sin \theta_{2}+\cos ^{2} \theta_{1} \cos \theta_{2} \sin \theta_{2}\right)$ $+\dot{\theta}_{1}^{2}\left(\cos \theta_{2} \sin \theta_{2}-2 \cos ^{2} \theta_{1} \cos \theta_{2} \sin \theta_{2}-\cos ^{3} \theta_{2} \sin \theta_{2}+2 \cos ^{2} \theta_{1} \cos ^{3} \theta_{2} \sin \theta_{2}+\cos ^{4} \theta_{1} \cos \theta_{2} \sin \theta_{2}\right)$ $\left.+\dot{\theta}_{1} \dot{\theta}_{2}\left(2 \cos \theta_{1} \sin \theta_{1} \cos ^{2} \theta_{2}-2 \cos \theta_{1} \sin \theta_{1} \cos ^{4} \theta_{2}\right)\right)+\left(\frac{2 \xi_{2}}{\Omega} \dot{\theta}_{2}+\frac{\theta_{2}-\phi_{2}}{\lambda \Omega^{2}}-\frac{1}{\Omega^{2}} \frac{\cos \theta_{2} \sin \theta_{2}}{\sqrt{1-\sin ^{2} \theta_{1}-\sin ^{2} \theta_{2}}}\right)$ $\times\left(1-2 \cos ^{2} \theta_{1}-2 \cos ^{2} \theta_{2}+\cos ^{4} \theta_{1}+\cos ^{4} \theta_{2}+2 \cos ^{2} \theta_{1} \cos ^{2} \theta_{2}\right)$ $=F \sin \varphi \sin \tau \cos \theta_{1}\left(1-2 \cos ^{2} \theta_{1}-2 \cos ^{2} \theta_{2}+\cos ^{4} \theta_{1}+\cos ^{4} \theta_{2}+2 \cos ^{2} \theta_{1} \cos ^{2} \theta_{2}\right)$,

where the dot now denotes $d / d \tau$, with $\tau=\omega_{e} t, \Omega=\omega_{e} / \omega_{p}, F=F_{b} / l$, and $C_{i} / m l^{2}=2 \xi_{i} / \Omega\left(\xi_{i}\right.$ are the damping factors). Geometrical and inertial nonlinearities are seen to occur in (5) and (6).

\section{Nonlinear behavior and imperfection sensitivity analysis}

3.1. Static analysis. The nonlinear behavior of the imperfect system in the absence of dynamic excitation can be described by the following set of two coupled nonlinear equations obtained from (2)

$$
\left(\theta_{1}-\phi_{1}\right)-\lambda \frac{\cos \theta_{1} \sin \theta_{1}}{\sqrt{1-\sin ^{2} \theta_{1}-\sin ^{2} \theta_{2}}}=0, \quad\left(\theta_{2}-\phi_{2}\right)-\lambda \frac{\cos \theta_{2} \sin \theta_{2}}{\sqrt{1-\sin ^{2} \theta_{1}-\sin ^{2} \theta_{2}}}=0 .
$$

When $k_{1}=k_{2}=k$, the perfect model $(\phi=\psi=0)$ displays two coincident buckling loads, $P_{\mathrm{cr} 1}=P_{\mathrm{cr} 2}=$ $P_{\mathrm{cr}}=k / l$, and orthogonal buckling modes $\theta_{1},\{1,0\}^{T}$, and $\theta_{2},\{0,1\}^{T}$. Figure 2a shows the fundamental path $\left(\theta_{1}=\theta_{2}=0\right)$ for the perfect system, which is stable up to the static critical load $(\lambda=1)$, and the four possible postbuckling paths: the two ascending unstable paths, which correspond to the two uncoupled solutions (either $\theta_{1}$ or $\theta_{2}$ is zero), and the two descending unstable orthogonal paths at $45^{\circ}$, which are the solutions of the coupled system (7). The important fact to note is that interaction of the buckling modes $\theta_{1}$ and $\theta_{2}$ conspires to produce the descending unstable paths and imperfection sensitivity, although each mode taking place alone exhibits no imperfection sensitivity [Bažant and Cedolin 1991]. Figure 2b shows the nonlinear behavior of the imperfect system considering $\phi=1^{\circ}$ and $\psi=0^{\circ}$. The multiple bifurcation in Figure $2 \mathrm{a}$ is destroyed by the imperfection. In this case, the imperfect column under increasing static loading displays a stable nonlinear equilibrium path contained in the $x \times z$ plane since $\psi=0^{\circ}$ (see Figure 1), which becomes unstable due to a subcritical pitchfork bifurcation. The critical load is lower than that of the perfect system. Several unstable complementary paths corresponding to the perturbed unstable postbuckling paths of Figure 1a are observed. These unstable paths control the global dynamics of the system. Figure 2c shows the response of the imperfect system with $\phi=1^{\circ}$ and $\psi=45^{\circ}$. In this case, the nonlinear stable path loses stability at a limit point and the maximum load is even lower than in the previous case. Again, several unstable complementary paths are observed. The load-carrying capacity of the system decreases as $\phi$ and $\psi$ increase, as illustrated by the imperfection sensitivity curves shown in Figure 3, where the critical load of the imperfect system is plotted as a function of the imperfection magnitude $\phi$ for selected values of $\psi$. The lowest critical loads are obtained for $\psi=45^{\circ}$ when the maximum modal coupling occurs.

Much of the global behavior and dynamics of a structural system can be understood from the topological structure of its potential energy function. For a static load level $\lambda=0.9$, Figure 4 shows the 


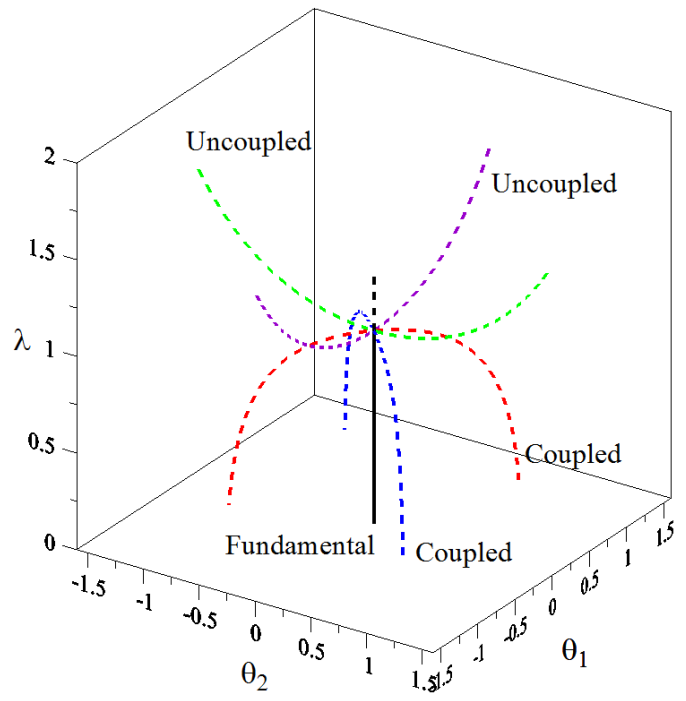

(a) Perfect system

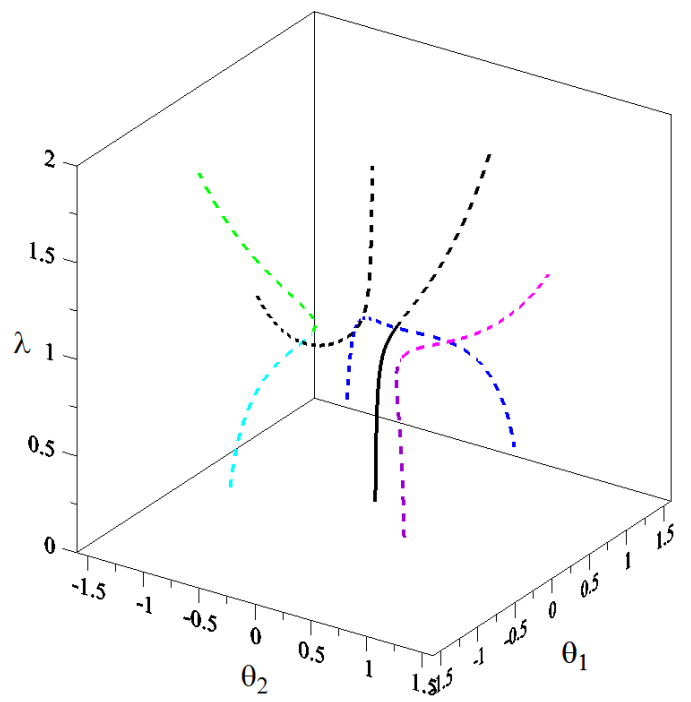

(b) Imperfect system, $\phi=1^{\circ}$ and $\psi=0^{\circ}$

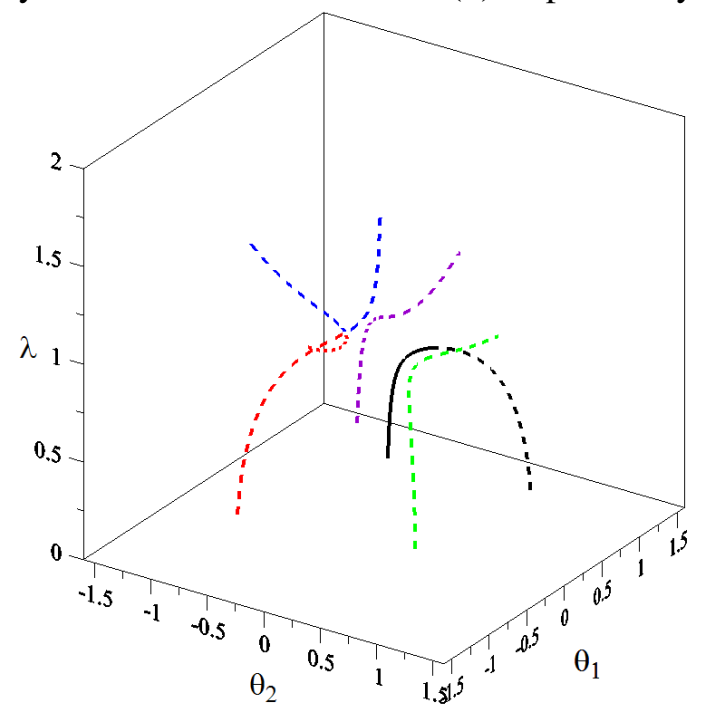

(c) Imperfect system, $\phi=1^{\circ}$ and $\psi=45^{\circ}$

Figure 2. Equilibrium paths of the perfect and imperfect systems.

equipotential curves for the three cases analyzed in Figure 2. The perfect system, Figure 4a, displays the four symmetric saddles corresponding to the four unstable postbuckling descending branches shown in Figure 2a and a minimum corresponding to the stable prebuckling solution. The saddles and their invariant manifolds separate the initial conditions that lead to bounded solutions surrounding the prebuckling configuration - which identify the so-called safe region [Soliman and Thompson 1989; Rega and Lenci 2005] — from the unbounded escape solutions. For $\phi=1^{\circ}$ and $\psi=0^{\circ}$, Figure $4 \mathrm{~b}$ shows that the safe region is bounded by the two saddles corresponding to the blue equilibrium path in Figure $2 \mathrm{~b}$. There is a significant decrease in the area of the safe region due to the imperfection. For $\phi=1^{\circ}$ and 




Figure 3. Imperfection sensitivity of Augusti's model.

$\psi=45^{\circ}$, as shown in Figure 4c, the safe region is bounded by the saddle with the lowest potential energy among the four saddles and is much smaller than in the previous case. The saddle corresponds to the unstable black equilibrium path in Figure 2c. As illustrated by these results, the imperfections not only decrease the load-carrying capacity of the structure, but also the set of initial conditions that lead to safe bounded motions around the equilibrium configuration. The knowledge of these frontiers helps the designer to separate the phase space into safe and unsafe domains and evaluate the degree of safety of the system. The frontiers are associated with the stable and unstable manifolds of the saddles in the conservative system, whose two-dimensional projections are shown in Figure 5. For the perfect system there are two pairs of heteroclinic orbits, each pair connecting two opposite saddles at $\pm 45^{\circ}$ (Figure 5a). For the imperfect system with $\phi=1^{\circ}$ and $\psi=0^{\circ}$, Figure $5 \mathrm{~b}$ shows that the safe region is bounded by two homoclinic orbits, while for $\phi=1^{\circ}$ and $\psi=45^{\circ}$, Figure $5 \mathrm{c}$ shows that there is only one homoclinic orbit. In each case, the relevant manifolds lie on a four-dimensional hypersurface that bounds the initial conditions leading to bounded solutions around the trivial prebuckling solution, that is, the interior of this region is filled with a continuous family of stable trajectories. The equation of this surface can be obtained by the principle of conservation of total energy, equating the sum of expressions (2) and (3) to the value of the total energy at one of the relevant saddles, that is

$$
T\left(\theta_{i}, \dot{\theta}_{i}\right)+V\left(\theta_{i}\right)=V_{\text {saddle }}
$$

Three-dimensional sections $\left(\theta_{1} \times \theta_{2} \times \dot{\theta}_{1}\right)$ of this four-dimensional region are shown in Figure 6, considering $\lambda=0.9$ and $\omega_{p}=1.0 \mathrm{~s}^{-1}$. These sections show clearly the sharp decrease in the safe region with the imperfection. This safe hypervolume decreases swiftly as the static load increases and vanishes at the critical point. So, near a bifurcation point, even very small perturbations may lead to escape from the prebuckling well. Since all structures work in a dynamical environment, an appropriate safety 


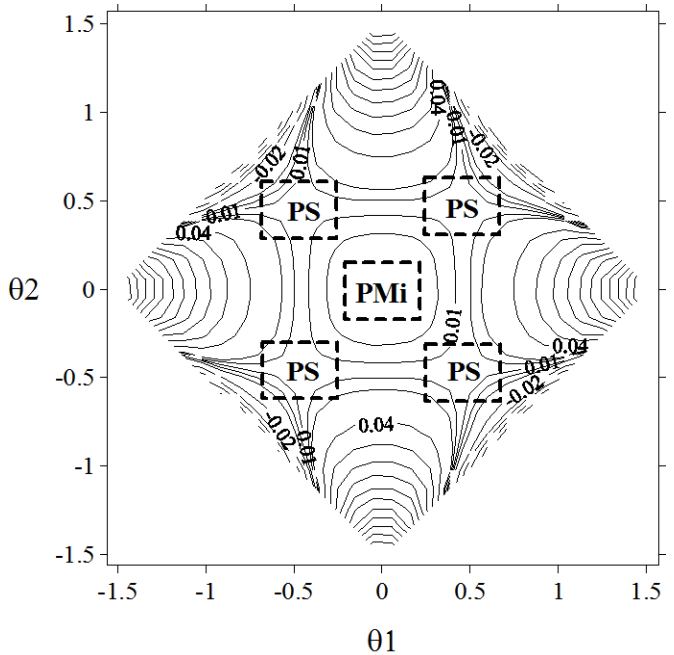

(a) Perfect system

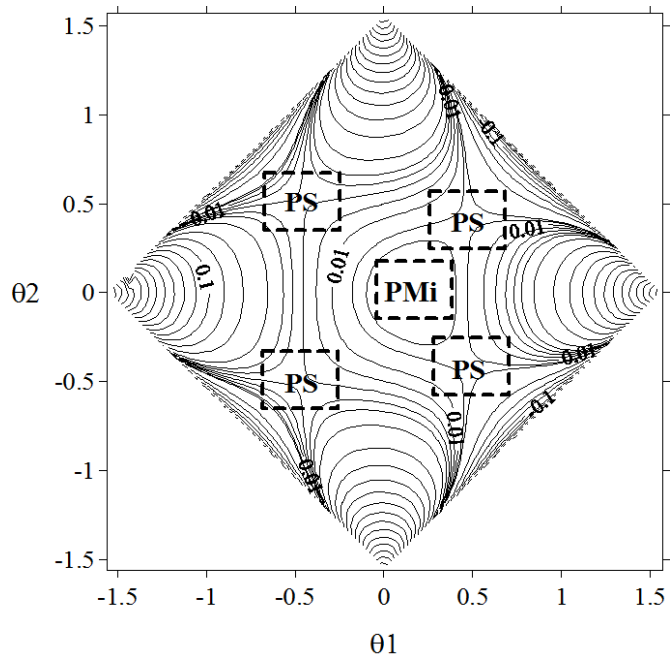

(b) Imperfect system, $\phi=1^{\circ}$ and $\psi=0^{\circ}$

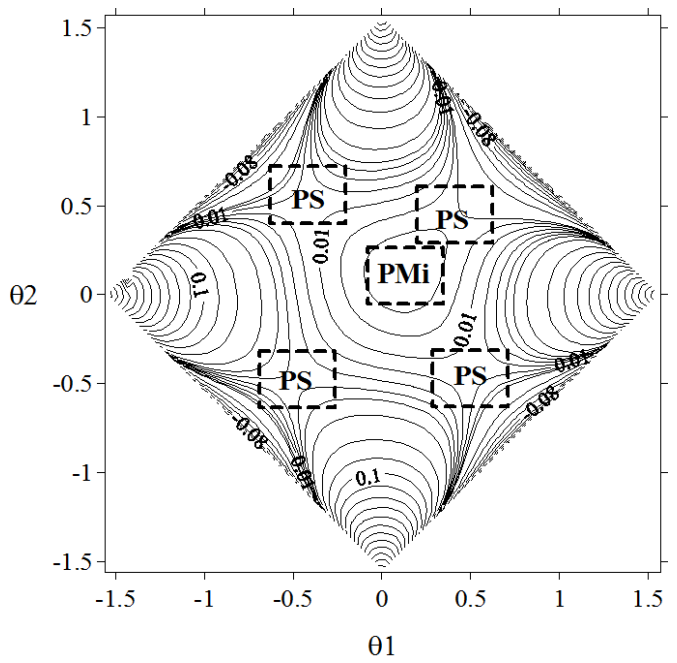

(c) Imperfect system, $\phi=1^{\circ}$ and $\psi=45^{\circ}$

Figure 4. Curves of equal potential energy for $\lambda=0.9$. PS: Saddles. PMi: Stable position corresponding to a local minimum.

factor based on the geometry and size of the safe region and its variation with load and imperfections must be used in design. Moreover, as structural systems are usually lightly damped, the response of the real structure will only depart lightly from the conservative case. An analysis of the safe region gives information on the maximum allowable displacements and velocities. These quantities must also be referred to in vibration control to specify the upper bound of allowable disturbances.

3.2. Nonlinear dynamic analysis. Figure 7 shows the stability boundaries in force frequency-amplitude control space for the perfect system and a forcing direction $\varphi=0^{\circ}$. The escape load, $F_{\text {esc }}$, corresponds to escape of the response from the prebuckling potential well in a slowly evolving system (dynamic 
(a) Perfect system

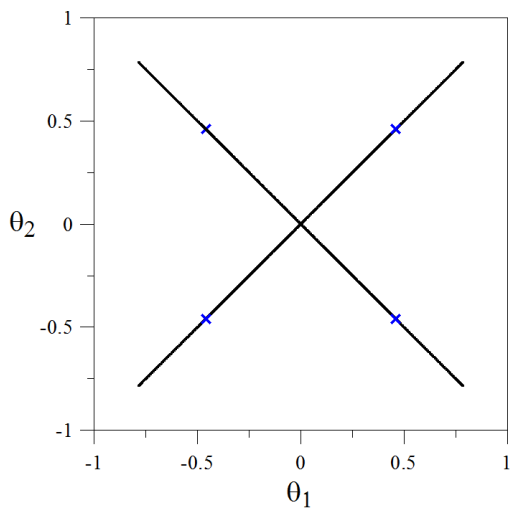

(a.1) Plane $\theta_{1} \times \theta_{2}$

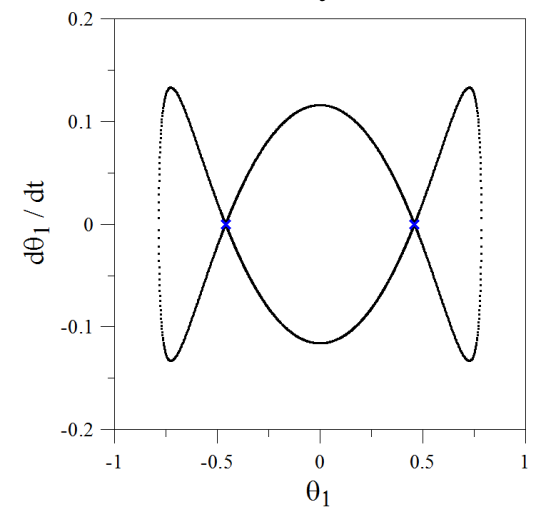

(a.2) Plane $\theta_{1} \times \dot{\theta}_{1}$

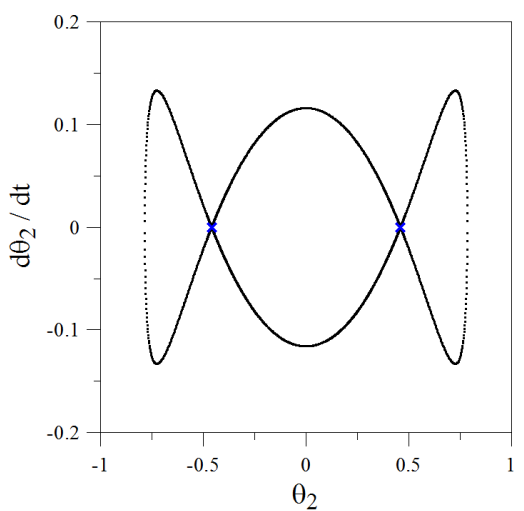

(a.3) Plane $\theta_{2} \times \dot{\theta}_{2}$

(b) Imperfect system, $\phi=1^{\circ}$ and $\psi=0^{\circ}$

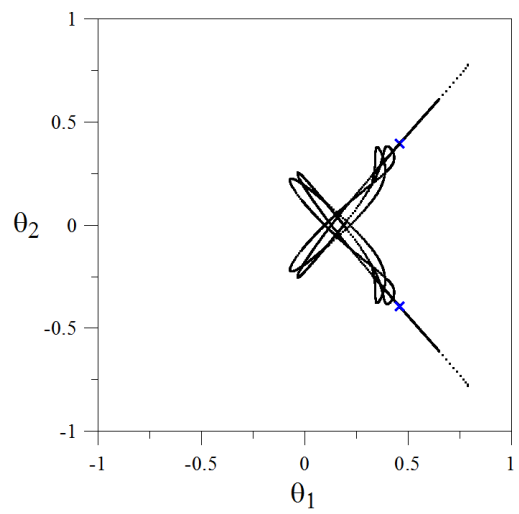

(b.1) Plane $\theta_{1} \times \theta_{2}$

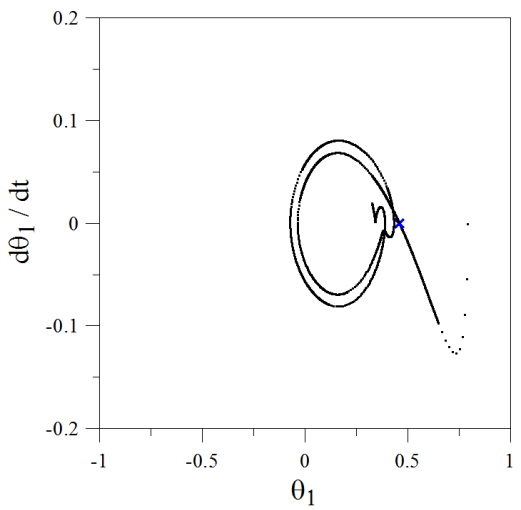

(b.2) Plane $\theta_{1} \times \dot{\theta}_{1}$

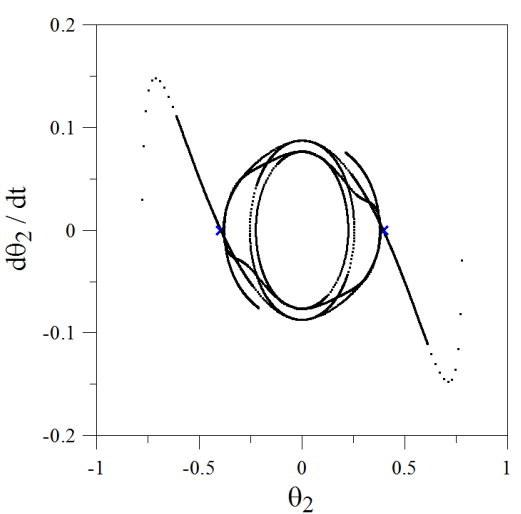

(b.3) Plane $\theta_{2} \times \dot{\theta}_{2}$

(c) Imperfect system, $\phi=1^{\circ}$ and $\psi=45^{\circ}$

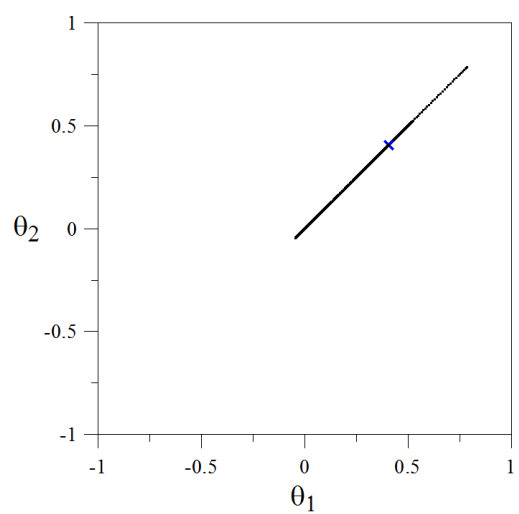

(c.1) Plane $\theta_{1} \times \theta_{2}$

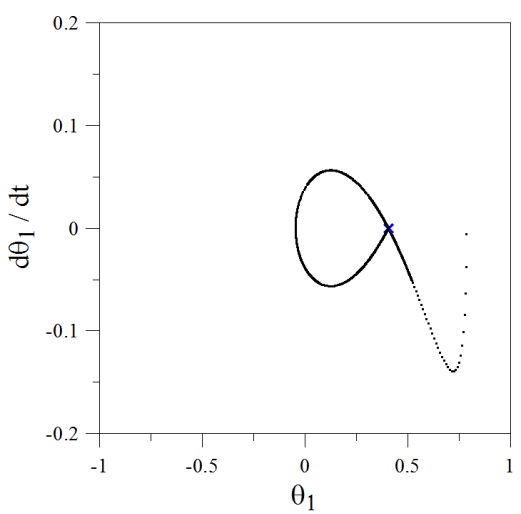

(c.2) Plane $\theta_{1} \times \dot{\theta}_{1}$

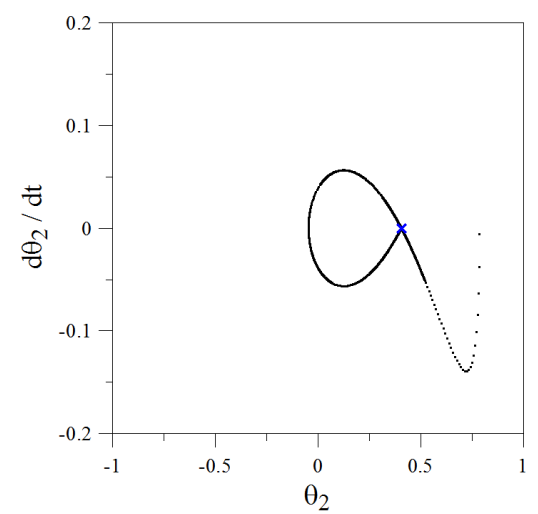

(c.3) Plane $\theta_{2} \times \dot{\theta}_{2}$

Figure 5. Two-dimensional projections of the stable and unstable manifold of the saddles that limit the safe region for $\lambda=0.9$ and $\omega_{p}=1.0 / \mathrm{s}$. 




(a) Perfect system

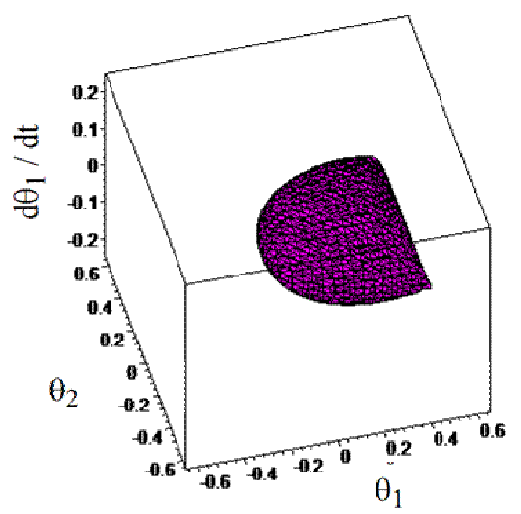

(b) Imperfect system $\phi=1^{\circ}$ and $\psi=0^{\circ}$

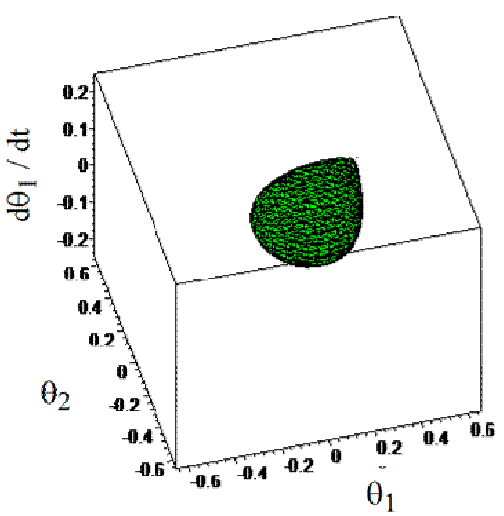

(c) Imperfect system $\phi=1^{\circ}$ and $\psi=45^{\circ}$

Figure 6. Three-dimensional sections of safe prebuckling region. $\lambda=0.9$ and $\omega_{p}=1.0 / \mathrm{s}$.

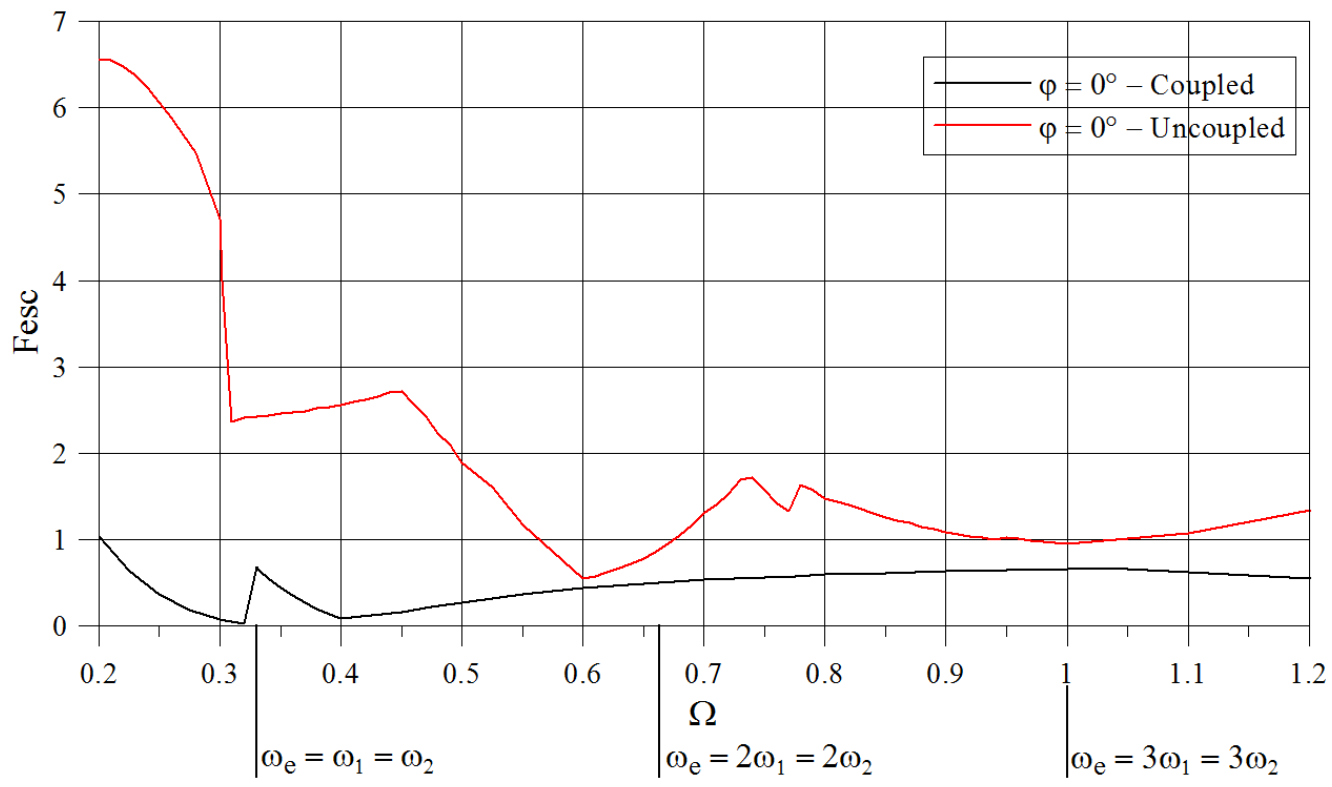

Figure 7. Stability boundaries in force control space (load versus forcing frequency) for the forcing direction $\varphi=0^{\circ}$, considering the coupled and uncoupled cases. $F_{\text {esc }}$ : escape load.

buckling). These curves ensue from several bifurcation diagrams obtained by increasing slowly the forcing amplitude while holding the frequency constant [Gonçalves et al. 2009; Orlando 2010]. Denoting with $\omega_{i}, i=1,2$, the natural frequencies of the two linear vibration modes of the system, a large range of forcing frequencies is considered, which includes the fundamental parametric resonances $\left(\omega_{e}=\omega_{i}\right)$ of the two modes and their principal subharmonic parametric resonances, of order $\frac{1}{2}$ (that is, $\omega_{e}=2 \omega_{i}$ ) and $\frac{1}{3}\left(\omega_{e}=3 \omega_{i}\right)$. For the perfect system $\omega_{1}=\omega_{2}$, the fundamental and principal resonances correspond 
to the nondimensional forcing frequency values $\Omega=\frac{1}{3}, \Omega=\frac{2}{3}$, and $\Omega=1$, respectively, whereas for the imperfect system the two natural frequencies differ from each other [Orlando 2010] and the same occurs for the relevant resonant conditions.

Two cases are considered in Figure 7: the uncoupled case, when perturbations only in $\theta_{1}$ and $\dot{\theta}_{1}$ are considered and only these coordinates are excited, and the coupled case, when very small perturbations in $\theta_{2}$ and $\dot{\theta}_{2}$ are also considered after each load step $\left(\theta_{2}=\dot{\theta}_{2}=0.001\right)$, causing the coupling of the two modes. For the uncoupled case, the lowest values of the escape load occur in the neighborhood of
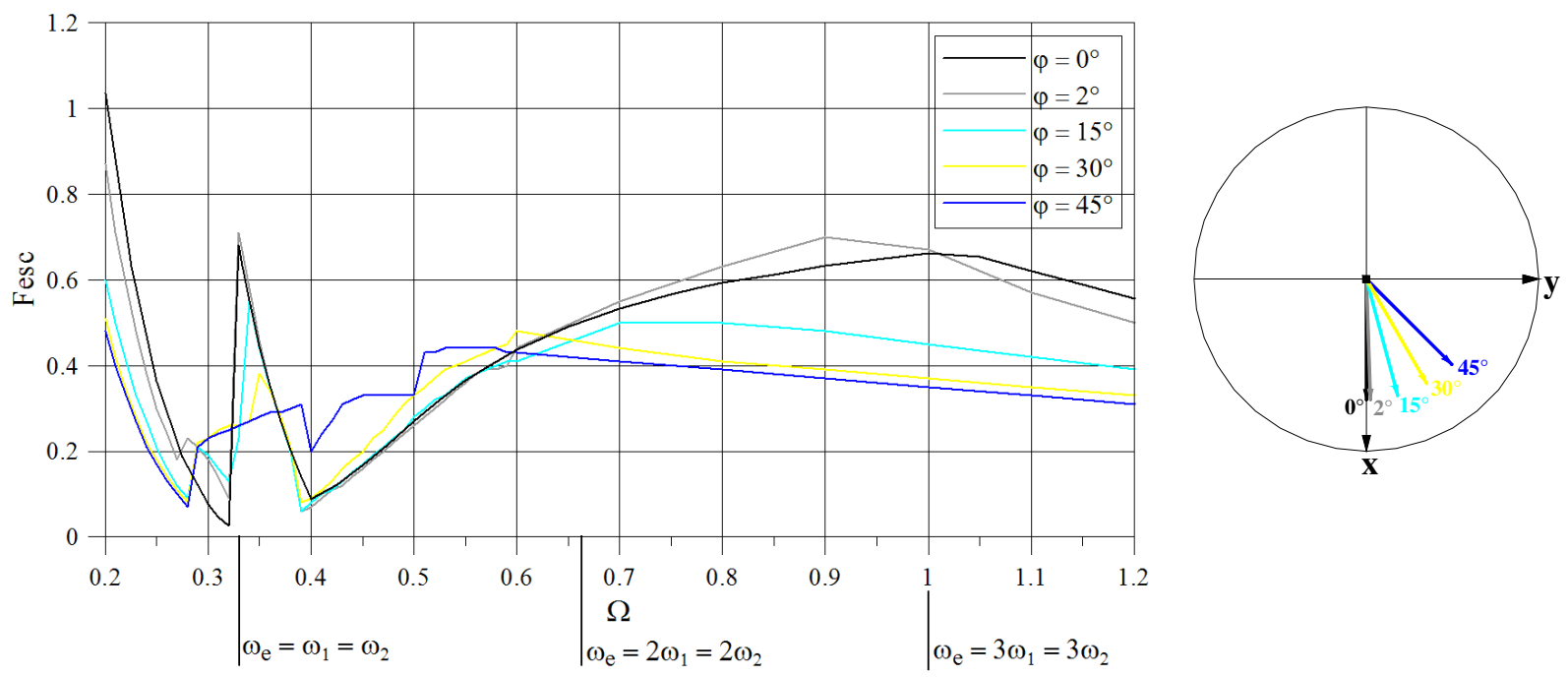

(a) Perfect system
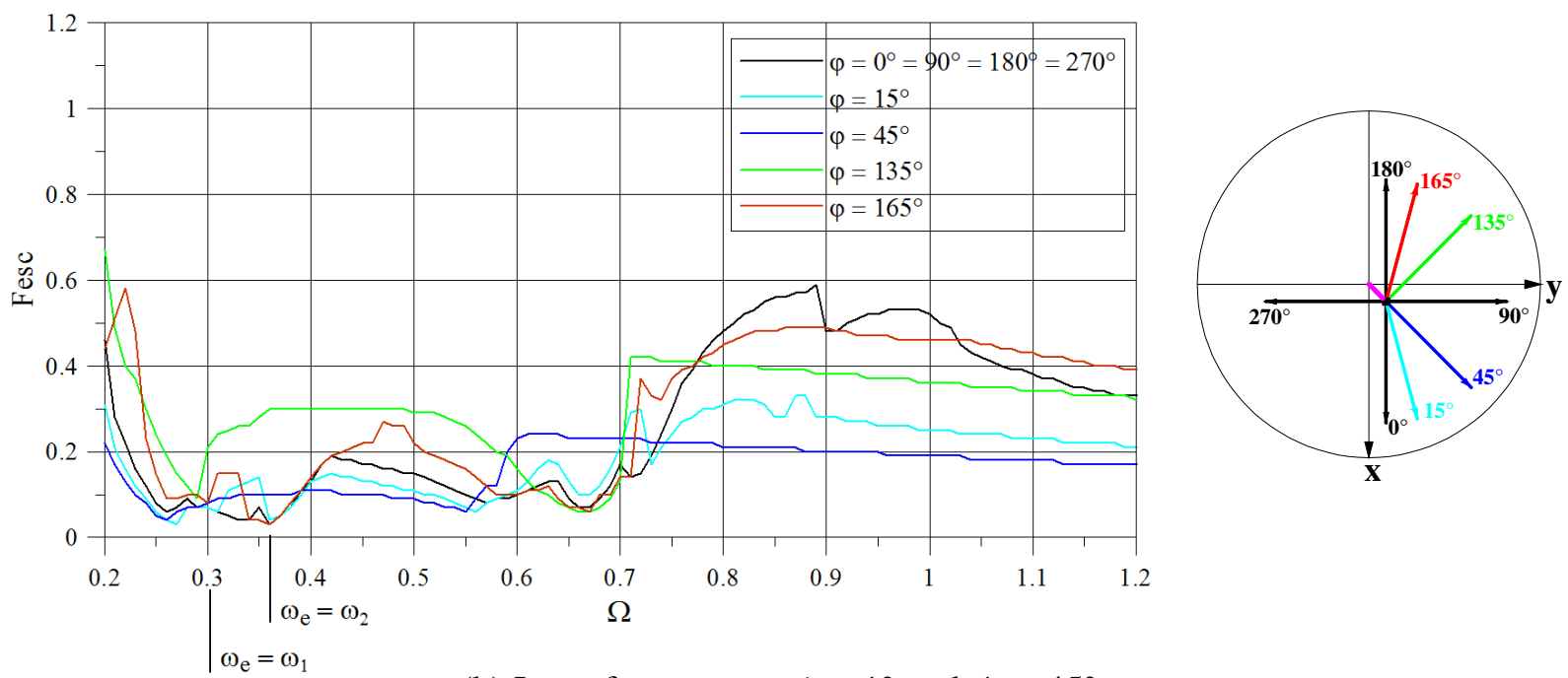

(b) Imperfect system, $\phi=1^{\circ}$ and $\psi=45^{\circ}$

Figure 8. Stability boundaries in force control space (load versus forcing frequency) for different values of the forcing direction $\varphi$ (polar diagram) for perfect and imperfect systems. $F_{\text {esc }}$ : escape load. 


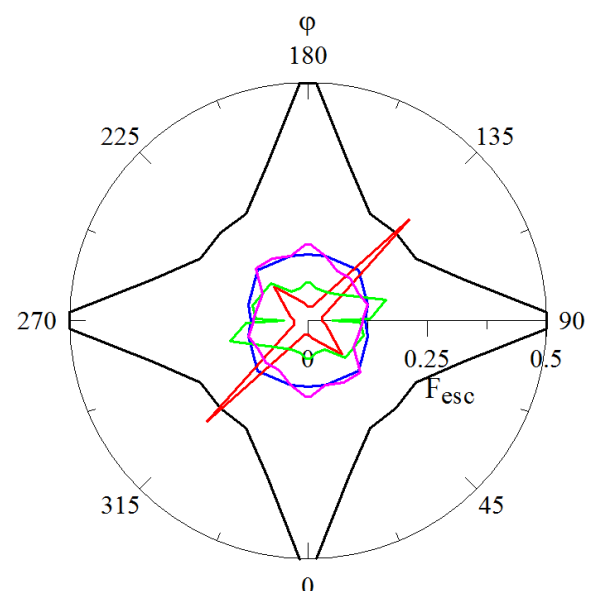

(a) $\omega_{e}=\omega_{1}$

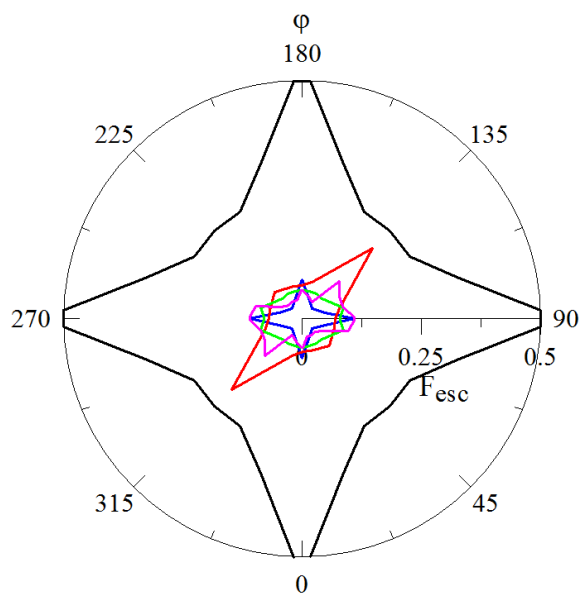

(b) $\omega_{e}=\omega_{2}$

Figure 9. Variation of the escape load with the forcing direction $\varphi$ for the resonance regions.

the principal resonances $\left(\Omega=\frac{2}{3}\right.$ and $\left.\Omega=1\right)$ of the two coinciding modes, as expected in a condition of parametric excitation. In contrast, quite high $F_{\text {esc }}$ values do occur in the region of fundamental resonance $\left(\Omega=\frac{1}{3}\right)$. But for even very small values of $\theta_{2}$ and $\dot{\theta}_{2}$, which entail coupling of the two modes, a drastic reduction in the escape load is observed in the latter region along with an overall reduction in the whole excitation frequency range here analyzed. Indeed, there is a marked difference between the relevant stability boundaries in the two cases, corroborating the importance of modal coupling in Augusti's model.

Figure 8 shows the stability boundaries for different values of the forcing direction $\varphi$, respectively for the perfect system (Figure 8a) and for the imperfect system considering $\phi=1^{\circ}$ and $\psi=45^{\circ}$ (Figure 8b). Figure 8a shows that, as soon as coupling comes into play due to the excitation $\left(\varphi \neq 0^{\circ}\right)$, the escape load decreases mostly in the larger frequency range, where it is higher for $\varphi \neq 0^{\circ}$, with the major reduction occurring for $\varphi=45^{\circ}$, namely, when the coupling effect is the highest. When imperfection is added (Figure 8b), a significant decrease of the dynamic buckling load is observed with respect to the perfect system (Figure $8 \mathrm{a}$ ) for any value of the forcing frequency $\Omega$, with the maximum reduction still occurring for $\varphi=45^{\circ}$, as expected, owing to the considered $\psi=45^{\circ}$ imperfection value.

Overall, as in the static case, the dynamic buckling load displays high imperfection sensitivity with drastic effects on the safety of the system. Figure 9 shows the variation of the escape load, $F_{\text {esc }}$, for the perfect and imperfect columns with the forcing direction $\varphi$, by distinguishing between the regions of fundamental resonance of the two DOFs, which do coincide in the perfect system (see Figure 8a) but are slightly different in the imperfect one (Figure 8b). For the imperfect case, different values of the imperfection direction $\psi$ are considered and an initial column inclination $\phi=1^{0}$ is adopted. The results show a high imperfection sensitivity for all values of $\varphi$. It is observed that the results are also sensitive to the imperfection direction $\psi$, with the ensuing coupling effect entailing the strongest reduction of escape load with respect to the perfect system when the latter exhibits no coupling, that is, for $\varphi=0^{\circ}$.

Figure 10 shows the variation of the basin of attraction of the bounded solution between perfect and imperfect systems, when considering a forcing direction $\varphi=0^{\circ}$, a forcing magnitude $F=0.1$, and a forcing frequency $\Omega=\frac{1}{3}$. The cross section of the basin of attraction of the perfect system (Figure 10a) 
(a) Perfect system

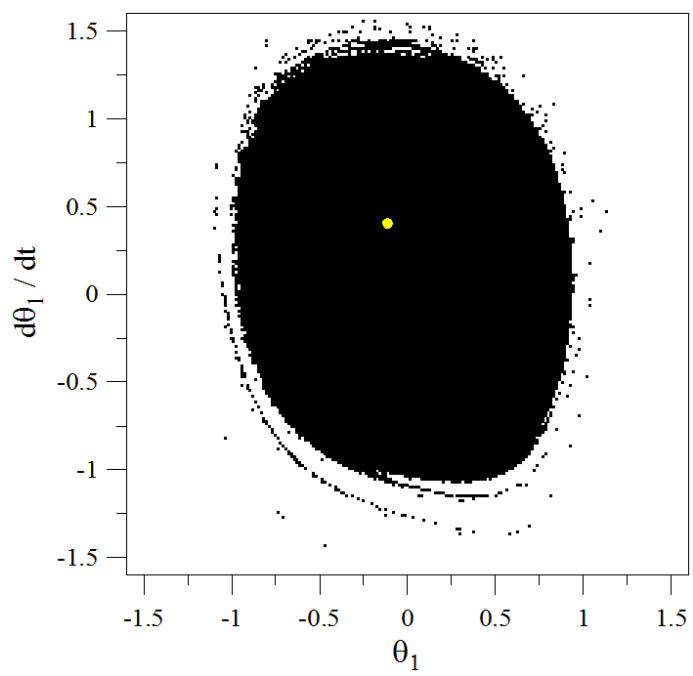

(b) Imperfect system, $\phi=1^{\circ}$ and $\psi=45^{\circ}$

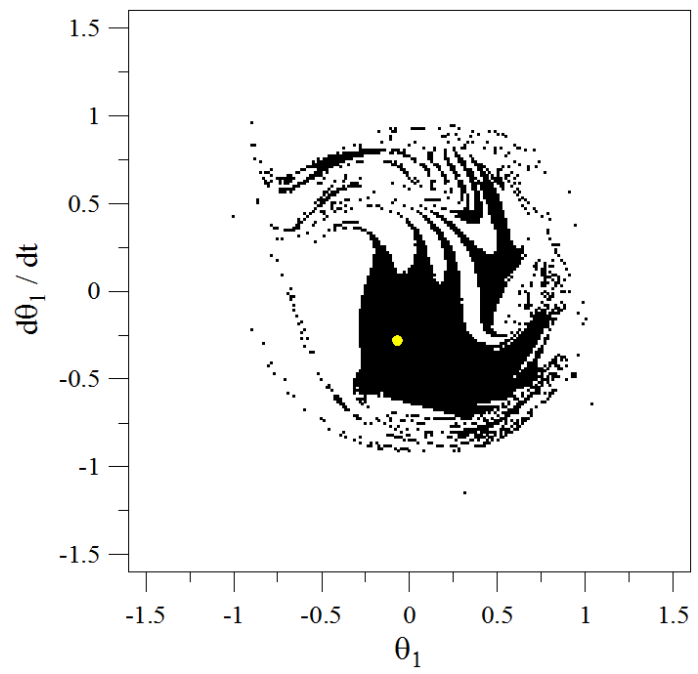

Figure 10. Variation of the basin of attraction with the geometric imperfection $\left(\Omega=\frac{1}{3}\right.$, $\left.F=0.1, \varphi=0^{\circ}\right)$.

is still relatively integer (nonfractal) since the considered $F=0.1$ value is below the escape threshold (see Figure 8a). In contrast, for the imperfect system with $\phi=1^{\circ}$ and $\psi=45^{\circ}$ (Figure 10b), a drastic reduction of the safe basin area is observed, since the forcing magnitude is now slightly smaller than the corresponding escape load (see Figure $8 \mathrm{~b} ; F_{\text {esc }}=0.11$ ).

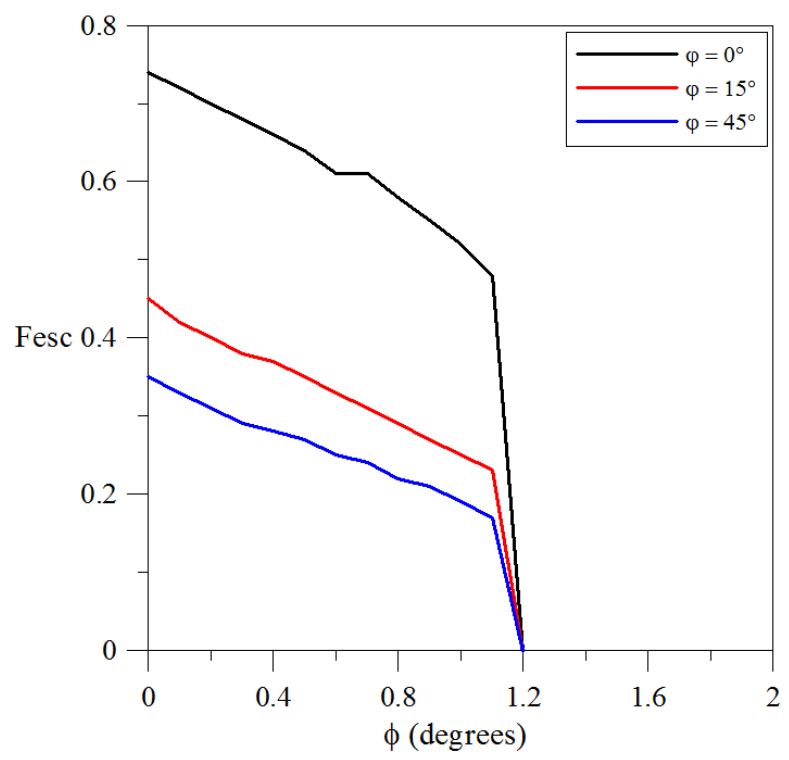

Figure 11. Variation of the escape load with the column initial inclination $\phi$ for $\Omega=1$ and $\psi=45^{\circ}$. 
Finally, Figure 11 shows the variation of the escape load with the column initial inclination $\phi$. The escape load reduction already occurring for the perfect system owing to the $\varphi \neq 0^{\circ}$ excitation direction is clearly visible for $\phi=0^{\circ}$. As the initial inclination $\phi$ increases the escape load smoothly decreases, but at $\phi=1.2^{\circ}$ it suddenly falls down to zero, which corresponds to the complete annihilation of the basin of attraction for any excitation direction (also for the uncoupled case, $\varphi=0^{\circ}$ ). This shows that even very small imperfections may have a remarkable influence on the stability and safety of the structure and, in particular, that the residual dynamic integrity of the system [Rega and Lenci 2005] associated with the nonvanishing value of the escape load for $\phi=1^{\circ}$ actually corresponds to a very dangerous system configuration from a nonlinear dynamics viewpoint.

\section{Conclusions}

In this paper the influence of geometric imperfections on the static and dynamic behavior of Augusti's model is studied through a detailed parametric analysis. The inherent strong modal coupling of the model leads to various unstable postbuckling solutions that control the geometry of the safe prebuckling potential well and, consequently, the global behavior of the system under dynamic loads. The initial imperfections not only decrease the load-carrying capacity of the structure, but also decrease substantially the safe region where initial conditions lead to bounded solutions within the prebuckling well. This region is swiftly reduced as the static load approaches the critical value.

The results also highlight the influence of the imperfections on the forced response of the system under harmonic base excitation with varying the horizontal direction. For any excitation frequency and for all nonvanishing forcing directions, the imperfection considerably reduces the escape load and the safe basin area, decreasing the safety of the system.

The analysis of Augusti's model, as an archetypal model of a large class of structures liable to buckling that display a strong modal coupling and imperfection sensitivity, illustrates the tools and steps necessary for a rational evaluation of system safety and dynamic integrity.

\section{References}

[Augusti 1964] G. Augusti, "Stabilità elastiche elementari in presenza di grandi spostamenti", Atti. Accad. Sci. Fis. Mat. Napoli Ser. $3 a$ 4:5 (1964).

[Bažant and Cedolin 1991] Z. P. Bažant and L. Cedolin, Stability of structures, Oxford University Press, Oxford, 1991.

[Brubak and Hellesland 2007] L. Brubak and J. Hellesland, "Semi-analytical postbuckling and strength analysis of arbitrarily stiffened plates in local and global bending", Thin-Walled Struct. 45:6 (2007), 620-633.

[Chen and Yu 2006] H. Chen and W. Yu, "Postbuckling and mode jumping analysis of composite laminates using an asymptotically correct, geometrically non-linear theory", Int. J. Non-Linear Mech. 41:10 (2006), 1143-1160.

[Croll and Walker 1972] J. G. Croll and A. C. Walker, Elements of structural stability, 1st ed., Macmillan, London, 1972.

[Dinis et al. 2007] P. B. Dinis, D. Camotim, and N. Silvestre, "FEM-based analysis of the local-plate/distortional mode interaction in cold-formed steel lipped channel columns", Comput. Struct. 85:19-20 (2007), 1461-1474.

[Elishakoff et al. 1996] I. Elishakoff, S. Marcus, and J. H. Starnes, Jr., "On vibrational imperfection sensitivity of Augusti's model structure in the vicinity of a non-linear static state", Int. J. Non-Linear Mech. 31:2 (1996), 229-236.

[Gonçalves et al. 2009] P. B. Gonçalves, D. Orlando, G. Rega, and S. Lenci, "Influence of modal coupling on the nonlinear dynamics of Augusti's model”, ASME Conf. Proc. 2009:49019 (2009), 1351-1358.

[Heijden 2008] A. M. A. Van der Heijden, W. T. Koiter's elastic stability of solids and structures, Cambridge University Press, Cambridge, 2008. 
[Iooss and Joseph 1980] G. Iooss and D. D. Joseph, Elementary stability and bifurcation theory, Springer, New York, 1980. 2nd ed. published in 1990.

[Kiymaz 2005] G. Kiymaz, "FE based mode interaction analysis of thin-walled steel box columns under axial compression", Thin-Walled Struct. 43:7 (2005), 1051-1070.

[Koiter 1945] W. T. Koiter, Over de stabiliteit van het elastisch evenwicht, Ph.D. thesis, Delft University of Technology, 1945, available at http://tinyurl.com/Koiter-WT-1945-Thesis. Translated in On the stability of elastic equilibrium, NASA Technical Translation NASA-TT-F-10833 (1967) and The stability of elastic equilibrium, Air Force Flight Dynamics Laboratory report AFFDL TR 70-25 (1970), http://contrails.iit.edu/DigitalCollection/1970/AFFDLTR70-025.pdf.

[Kołakowski 2007] Z. Kołakowski, "Some aspects of dynamic interactive buckling of composite columns", Thin-Walled Struct. 45:10-11 (2007), 866-871.

[Naschie 1990] M. S. El Naschie, Stress, stability and chaos in structural engineering, an energy approach, McGraw-Hill, London, 1990.

[Orlando 2010] D. Orlando, Dinâmica não-linear, instabilidade e controle de sistemas estruturais com interação modal, Ph.D. thesis, Pontifícia Universidade Católica, Rio de Janeiro, 2010.

[Pignataro et al. 1991] M. Pignataro, N. Rizzi, and A. Luongo, Stability, bifurcation and postcritical behaviour of elastic structures, Developments in Civil Engineering 39, Elsevier, Amsterdam, 1991.

[Quinn et al. 2007] D. D. Quinn, J. P. Wilber, C. B. Clemons, G. W. Young, and A. Buldum, "Buckling instabilities in coupled nano-layers", Int. J. Non-Linear Mech. 42:4 (2007), 681-689.

[Raftoyiannis and Kounadis 2000] I. G. Raftoyiannis and A. N. Kounadis, "Dynamic buckling of 2-DOF systems with mode interaction under step loading”, Int. J. Non-Linear Mech. 35:3 (2000), 531-542.

[Rega and Lenci 2005] G. Rega and S. Lenci, "Identifying, evaluating, and controlling dynamical integrity measures in nonlinear mechanical oscillators", Nonlinear Anal. Theory Methods Appl. 63:5-7 (2005), 902-914.

[Soliman and Thompson 1989] M. S. Soliman and J. M. T. Thompson, "Integrity measures quantifying the erosion of smooth and fractal basins of attraction", J. Sound Vib. 135:3 (1989), 453-475.

[Thompson and Hunt 1973] J. M. T. Thompson and G. W. Hunt, A general theory of elastic stability, Wiley, London, 1973.

[Thompson and Hunt 1984] J. M. T. Thompson and G. W. Hunt, Elastic instability phenomena, Wiley, London, 1984.

[Tvergaard 1973] V. Tvergaard, "Imperfection-sentitivity of a wide integrally stiffened panel under compression", Int. J. Solids Struct. 9:1 (1973), 177-192.

[Zocher 1933] H. Zocher, "The effect of a magnetic field on the nematic state", Trans. Faraday Soc. 29:140 (1933), 945-957.

Received 23 Jun 2010. Revised 17 Sep 2010. Accepted 15 Nov 2010.

DIEGO ORLANDO: dgorlando@gmail.com

Department of Civil Engineering, Pontifical Catholic University, Rio, Rua Marquês de São Vicente, 225, Gávea, 22453-900 Rio de Janeiro-RJ, Brazil

Paulo Batista Gonçalves: paulo@puc-rio.br

Department of Civil Engineering, Pontifical Catholic University, Rio, Rua Marquês de São Vicente, 225, Gávea, 22453-900 Rio de Janeiro-RJ, Brazil

GIUSEPPE REGA: giuseppe.rega@uniroma1.it

Dipartimento di Ingegneria Strutturale e Geotecnica, Università degli Studi di Roma 'La Sapienza', via Eudossiana 18, I-00184 Roma, Italy

STEFAno LencI: lenci@univpm.it

Dipartimento di Architettura, Costruzioni e Strutture, Università Politecnica delle Marche, via Brecce Bianche,

I-60131 Ancona, Italy 


\title{
JOURNAL OF MECHANICS OF MATERIALS AND STRUCTURES
}

\author{
jomms.org
}

Founded by Charles R. Steele and Marie-Louise Steele

EDITORS

Charles R. SteEle

DAVIDE BIGONI

Stanford University, USA

YASUHIDE SHINDO

University of Illinois at Urbana-Champaign, USA

Tohoku University, Japan

\section{EDITORIAL BOARD}

$\begin{aligned} \text { H. D. BUI } & \text { École Polytechnique, France } \\ \text { J. P. CARTER } & \text { University of Sydney, Australia } \\ \text { R. M. CHRISTENSEN } & \text { Stanford University, USA } \\ \text { G. M. L. GLADWELL } & \text { University of Waterloo, Canada } \\ \text { D. H. HODGES } & \text { Georgia Institute of Technology, USA } \\ \text { J. HUTCHINSON } & \text { Harvard University, USA } \\ \text { C. HWU } & \text { National Cheng Kung University, Taiwan } \\ \text { B. L. KARIHALOO } & \text { University of Wales, UK } \\ \text { Y. Y. KIM } & \text { Seoul National University, Republic of Korea } \\ \text { Z. MROZ } & \text { Academy of Science, Poland } \\ \text { D. PAMPLONA } & \text { Universidade Católica do Rio de Janeiro, Brazil } \\ \text { M. B. RUBIN } & \text { Technion, Haifa, Israel } \\ \text { A. N. SHUPIKOV } & \text { Ukrainian Academy of Sciences, Ukraine } \\ \text { T. TARNAI } & \text { University Budapest, Hungary } \\ \text { F. Y. M. WAN } & \text { University of California, Irvine, USA } \\ \text { P. WRIGGERS } & \text { Universität Hannover, Germany } \\ \text { W. YANG } & \text { Tsinghua University, China } \\ \text { F. ZIEGLER } & \text { Technische Universität Wien, Austria } \\ & \\ \text { PRODUCTION } & \text { contact@ msp.org } \\ \text { SILVIO LEVY } & \text { Scientific Editor }\end{aligned}$

Cover design: Alex Scorpan

Cover photo: Mando Gomez, www.mandolux.com

See http://jomms.org for submission guidelines.

JoMMS (ISSN 1559-3959) is published in 10 issues a year. The subscription price for 2011 is US \$520/year for the electronic version, and \$690/year (+\$60 shipping outside the US) for print and electronic. Subscriptions, requests for back issues, and changes of address should be sent to Mathematical Sciences Publishers, Department of Mathematics, University of California, Berkeley, CA 94720-3840.

JoMMS peer-review and production is managed by EditFLow ${ }^{\circledR}$ from Mathematical Sciences Publishers.

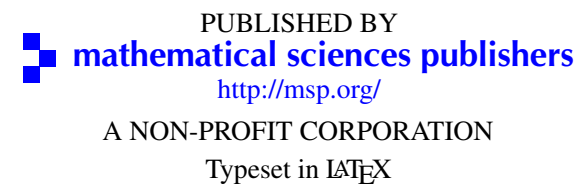

Copyright (C2011 by Mathematical Sciences Publishers 


\section{Journal of Mechanics of Materials and Structures}

\section{Volume 6, No. 7-8}

September-October 2011

\section{Special issue \\ Eleventh Pan-American Congress \\ of Applied Mechanics (PACAM XI)}

Preface

Adair R. Aguiar

949

Influence of specimen geometry on the Portevin-Le Châtelier effect due to dynamic strain aging

for the AA5083-H116 aluminum alloy

Rodrigo Nogueira de Codes and Ahmed Benallal

Dispersion relations for SH waves on a magnetoelectroelastic heterostructure with imperfect

interfaces

J. A. Otero, H. Calas, R. Rodríguez, J. Bravo, A. R. Aguiar and G. Monsivais

Numerical linear stability analysis of a thermocapillary-driven liquid bridge with magnetic stabilization

Yue Huang and Brent C. Houchens

Numerical investigation of director orientation and flow of nematic liquid crystals in a planar 1:4 expansion Pedro a. Cruz, Murilo F. Tomé, IAin W. Stewart and Sean McKee

Critical threshold and underlying dynamical phenomena in pedestrian-induced lateral vibrations of footbridges

Stefano LenCI and LAURA MARCHEgGiani

Free vibration of a simulation CANDU nuclear fuel bundle structure inside a tube

XUAN ZHANG and SHUdONG Yu

Nonlinear dynamics and sensitivity to imperfections in Augusti's model

D. Orlando, P. B. Gonçalves, G. Rega and S. LenCi

Active control of vortex-induced vibrations in offshore catenary risers: A nonlinear normal mode approach

CArlos E. N. MAZzilli and César T. SANCheS

Nonlinear electromechanical fields and localized polarization switching of piezoelectric macrofiber composites

Yasuhide Shindo, Fumio Narita, KoJi SATo and Tomo TAKeda

1089

Three-dimensional BEM analysis to assess delamination cracks between two transversely isotropic materials

Nicolás O. Larrosa, Jhonny E. Ortiz and Adrián P. Cisillino

Porcine dermis in uniaxial cyclic loading: Sample preparation, experimental results and modeling

A. E. Ehret, M. Hollenstein, E. MAzzA and M. Itskov

Analysis of nonstationary random processes using smooth decomposition

Rubens SAMpaio and Sergio Bellizzi

Perturbation stochastic finite element-based homogenization of polycrystalline materials

S. LePage, F. V. Stump, I. H. Kim and P. H. Geubelle

A collocation approach for spatial discretization of stochastic peridynamic modeling of fracture

Georgios I. Evangelatos and POL D. SPANOS 